\title{
The Importance of Tour Guides in Increasing the Number of Tourists at a Tourist Destination
}

\author{
Aram I. Nejmeddin, \\ Department of Tour-Guide, Erbil Administration Institute, Erbil Polytechnic University \\ Erbil, Kurdistan Region - Iraq
}

\begin{abstract}
Despite the presence of many naturally attractive tourist destinations, tourism in the Middle Eastern countries is affected because of the unfair media presentation of the geopolitical tensions in some parts of the region. In order to increase the number of tourists to this region, it becomes important to educate and train the tour guides to influence the tourists visiting these destinations by the quality level of their service and to provide destination-related information to the tourists to encourage them to revisit these destinations as well as recommend these destinations to their family and friends. In this context, this research, by undertaking a case study of the tourism in these destinations, provides a broader account of the role of tour guides in increasing the number of tourists to a tourist destination. The research also makes few recommendations in this connection along with future scope and opportunity of research.
\end{abstract}

Keywords - Destination and customer loyalty, tour guides, tour guide performance, tourist satisfaction.

\section{INTRODUCTION}

In recent times, there has been an increase in international tourism activities with more people travelling to different tourist destinations across the world (Şahin, 2012, p1). Importance of improving the level of customer service quality for achieving increased number of tourists to a particular tourist destination has gained momentum in the wake of competitiveness of tourist market place. Despite the increase in the global tourism activities, little attention is being paid to the impact of the role of tour guides in contributing to higher customer satisfaction levels (Sharpely \& Forster, 2003, p689). It needs to be recognized that tour guides are considered as the representatives of tourist destinations and countries, and they have a significant role to play in improving the tourist satisfaction and thus ensure an increase in the number of tourists to the destinations (Huang et al., 2010, p5). Middle east has emerged as one of the tourist attractions despite the ongoing geopolitical tensions in some of the regions. The negative media publicity representing the whole of middle east as a disturbed area may have a negative impact in promoting tourism in some of the better middle eastern destinations. Therefore, it becomes important that the tour guides make proper representations to the visitors to the middle eastern destinations for repeated visits and referrals to other tourists. In this context, this study seeks to analyse the importance of tour guides in increasing the number of tourists to the tourist destinations in middle eastern countries of turkey, Israel, Egypt, Kurdistan, Jordan, and the like.

\section{AIMS AND OBJECTIVES}

This research seeks to explore the impact of tour guide performance on the tourists' overall travelling experience and satisfaction and whether this could contribute to increase in the number of tourists for a given tourist destination. The objectives are:

1. To understand the role of tour guides in promoting a tourist destination

2. To identify the importance of the skills and behaviors of tour guides in enhancing tourist experience

3. To understand the relationship between the efficiency of tour guides and increase in number of tourists

\section{LITERATURE REVIEW}

The role of tour guide has been studied deeply by Cohen (1985, p7) According to Cohen $(1985, \mathrm{p} 12)$ the role of tour guide has the major components of instrumental, social, interactional, and communicative. Whilst the instrumental, active component is related to the smooth conducting and showing of the tour, the social component relates to structure and morale of the tourists. The interactional component means the role of tour guide to act as a middleman between the tourists and the local population. The communicative component refers to the knowledge of the tour guide about the information relating to the tourist destination and his ability to communicate with the tourists about such information within his knowledge. These functions of a tour guide suggest that a tour guide has to

Polytechnic Journal of Humanities and Social Sciences

Volume 1 No. 1 (2020); 06 pages; DOI: 10.25156/ptjhss.v1n1y2020.pp18-23

Received 30 January 2020; Accepted 7 February 2020; Regular research paper: Published 30 June 2020

Corresponding author's e-mail: aram.nejmeddin@epu.edu.iq

Copyright (C 2020 Aram I. Nejmeddin,. This is an open access article distributed under the Creative Commons Attribution License (CC BY-

NC-ND 4.0) 
represent a cultural interface between the tourists and the local population (Huang et al. 2010, p9).

Research has identified that tourism marketing and number of tourists visiting particular destinations is positively influenced by the personal qualities, adequacy of tourism knowledge, and practical experience of tour guides (Tsai et al. 2015, p825). The relationship between the efficiency of tour guides and improvements in tourism marketing in Istanbul was studied by (Cetinkaya \& Oter 2016, p45), to report the significant positive relationship between these variables. The following six themes have emerged and occurred from the research during the last five decades on the role of tour guides in tourism promotion. They are: (i) diversity and complexity and difficulty of the different dimension's sizes of tour guiding; (ii) role of the tour guide as interpreter and communicator of intercultural perspectives; (iii) contribution of tour guides to sustainability; (iv) expectations and satisfaction of tourists with respect to their experience with tour guides; (v) training, education, and professional development of research guides; and (vi) conceptualization of quality in tour guiding (Weiler, 2014, p1183). The increasing role of the tour guides in promoting ecotourism and nature-based tourism as also to interpret the tourist sites and motivate the tourists to not to disturb the ecology of the tourist sites has also been the subject of recent research (Yamada, 2011, p141) \& (Poudel and Nayaupane, 2013, p662). Review of the related literature points out to the fact that the personal qualities, knowledge, and personal experience of tour guides is most likely to result in increasing the number of tourists visiting a given destination. These variables are considered for this research as they have a significant impact on enhancing the tourist experience and satisfaction levels. Therefore, it can be hypothesized that:

H1: The level of personal qualities, knowledge, and personal experience of tour guides is likely to result in increased number of tourists to a given tourist destination.

The role of tour guides in tourism has been the subject matter of serious research, the absence of large number of quantitative studies. (Prakash, et al., 2010, p12) highlight the role of tourist guides in assuming pretending different roles in different contexts. The authors regard tour guiding and interpretation as the basic activity in the value chain of tourism industry. (Ap \& Wong, 2001, p553) remark that tour guides represent the key front-line players in the tourism industry, hence their knowledge and interpretive ability about the culture and attractions of tourist destinations are of extreme importance to convert the visit of the tourists to an experience. According to (Zhang \& Chow, 2004, p85), because of the ability of tour guides to provide valuable information about the tourist destinations, the tour guides can ensure the success of the respective tourist destinations. The tour guides have the capability to improve the image and reputation of the tourist destinations through producing quality service to tourists ( $\mathrm{Yu}$ et al., 2004, p11). The tour guides are expected to assume different roles because of the diversity in the functionality and the complexities involved in tour guiding. The different roles are summarized in the following table (Table 1).
TABLE I

DIFFERENT ROLES OF THE TOUR GUIDE

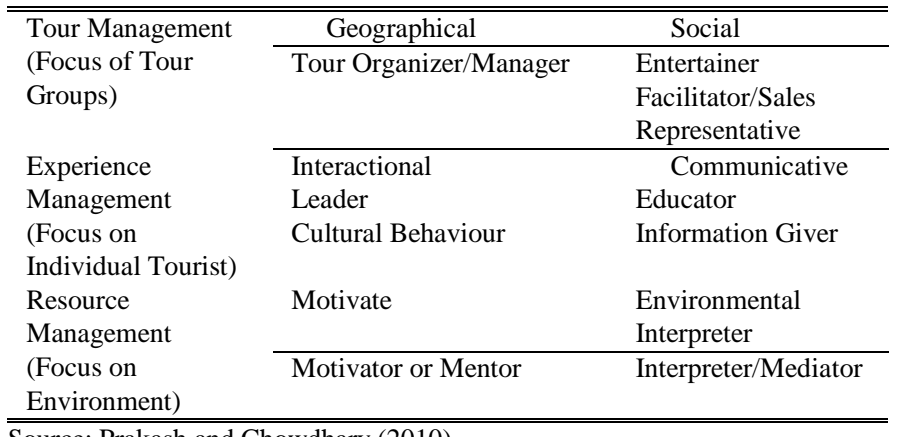

Source: Prakash and Chowdhary (2010)

The different roles of tour guides as tour organiser, tourist experience manager, and resource manager are considered as additional variables to conduct this research as they have a serious impact on tourist satisfaction. Therefore, the above review on the role of tour guide leads to the hypothesis that:

H2: The level of performance of tour guides in different roles will lead to increase in the number of tourists visiting a given tourist destination.

Customer satisfaction in the case of packaged tours is influenced largely by the quality level of tour services (Huang et al., 2010, p9). In this case, the customer satisfaction is found to have the constructs of satisfaction with tour service and satisfaction with the experience the tourists. Whilst factors like quality level of tour guide service, leisure activities, and food quality are responsible for customer satisfaction on tour service; tour guide service, shopping, and quality of leisure activities promote the customer satisfaction with respect to tour experience. Therefore, it follows that the tour guide service is one of the important variables in determining the increased number of visitors to a tourist destination as the quality of such service is responsible for tourists' satisfaction on tour service as well as tour experience. When there is an increase in the tourist satisfaction, it leads to increase in the number of tourists visiting a given tourist destination. This leads to the hypothesis that:

H3: The quality of services provided by tour guides significantly affects the number of tourists visiting a given tourist destination

\section{METHODOLOGY}

The case study analysis is the chosen methodology for this research as it allows a thorough, in-depth exploration of how tour guides influence the number of tourists at a given destination. This method is qualitative, which focuses more on the subjective individual experiences of the tourists. Case study as a research method has the advantage that it can be used within the context of its use (Yin, 2014, p404). The references used for the analysis are peer-reviewed journal articles written by Middle Eastern, Near Eastern, international authors, as well as scholarly textbooks written by both Western and Oriental scholars. The case study analysis exclusively focuses on the Middle Eastern countries of Turkey, Israel, Saudi Arabia, and Egypt. 
This research has chosen the Middle Eastern tourist destinations as the context for study, since Middle East is considered as a controversial hot region despite the presence of several natural tourist destinations. Any inconvenient geopolitical incident in any of the regions in the Middle East is reflected in all the countries in the region. This generalisation might be the effect of geographical ignorance or unfair publicity by the media. It is possible to reverse the negative stereotype on all the tourist destinations in this region by proper presentation by the tour guides to promote revisits by the tourists and referral to their friends and relatives. Therefore, this research is focused on the role of tourist guides in contributing to increased number of tourists since such a research becomes appropriate and important.

\section{RESULTS}

In the Republic of Turkey, the tourism industry is one of the most active and strong areas of businesses and has raised the country as one of the most well-liked tourist destinations in the world. In 2015, as reported by the Turkish Ministry of Culture and Tourism, the number of incoming tourists in the country went beyond 39 million with the overall revenue of roughly \$31 billion. Majority of these tourists are from the Middle East and Europe (Aldujayn, 2018, p 4).

Turkey's major city, Istanbul, presently accommodates roughly 12 million tourists from different countries with different purposes or goals. Hence, the city is a reliable reference for the impact of tour guides on tourist satisfaction or the number of tourists visiting a particular tourist destination. Tour guides in Istanbul are highly committed to their profession because of the strong belief in the country that tourists are excited, outgoing individuals originating from different nations and cultural backgrounds (Cetinkaya \& Oter, 2016, p47). The awareness of hospitality has traditionally been essential to the Turkish cultural identity and mentality. Hence, tour guides in this country have taken advantage of this quality to boost the performance of the local tourism industry.

Due to the naturally hospitable, welcoming Turkish culture, tour guides in Istanbul have a valuable role within the tourism industry and they fantastically satisfy the expectations, needs, and demands of visitors in Istanbul (Aldujayn, 2018, p8). The research findings of (Cetinkaya\& Oter, 2016, p10) show that large numbers of tourists in Istanbul plan to revisit the city. These tourists could potentially turn out to be loyal clients in the future. Moreover, the discovery that most of these tourists would want to revisit Istanbul show that the tour guides and tour operators in the locality understood the value of customer loyalty and satisfaction.

As regards word of mouth, the findings show that most of the tourists would refer Istanbul to their friends, family members, and relatives. This outcome is an indication that the tourists would automatically promote through word of mouth for the city in their native lands, which in result will the number of tourists to Istanbul rise in the near future or specific periods (Cetinkaya \& Oter, 2016, p12). In relation to the level of satisfaction, which the tourists identified from the tour guides' services, most of them were adequately and extremely satisfied. Knowledge is one of the tour guides' qualities that achieved an important part in getting this level of satisfaction (Cetinkaya \& Oter, 2016, p13). Based on these findings, it can be determined that the tour guides in Istanbul are competent capable and acceptable when it comes to knowledge, personality, and skills. Besides these factors, there are other explanations for the competence of tour guides in Turkey, such as having a comprehensive university education (Aldujayn, 2018, p 11).

Just like Turkey, Israel is also experiencing a significant increase in tourist arrivals. The tourism ministry reported that recently it has started several new programs planned to boost tourism, such as teaming up with major online travel agencies, reforming its marketing strategies to place emphasis and weight on recreation, supporting new immediate routes from the world's major cities, and improving the professional competence of their tour guides (Staff, 2018, p3). According to the Tourism Ministry, in 2018, Israel accommodated approximately 4 million visitors, which is a record-breaking development for the country. The ministry also reported that 40 per cent of these tourists are revisiting the country, which proves that Israel is a popular tourist destination (Staff, 2018, p3). But what made Israel's tourism largely successful is the capability of its tour guides to advance its political agenda.

Israel has used tourism as a political instrument. Tourism has served as a justification for the dominance and power of Israel over the people and land of Palestine. It is a propaganda tool that effectively spread to huge numbers of tourists the legitimacy of the Israel occupation. All of the tours in the country are led and escorted by thoroughly trained tour guides whose main goal is to relate the Israeli story to the tourists (Alqasis \& Kassis, 2015, p7). This story is formed through the removal of important details and by making sure that no interaction between local Palestinians and tourists occur. In order to ensure the success of this tour guiding agenda, the Israeli government proposed licensing tour guides yearly so as to guarantee their competence (Stein, 2008, p650). Alqasis \& Kassi (2015, p12) also reported that tourists in Israel prefer Israeli tour guides over Palestinians because the former can move easily through checkpoints and make the travelling experience more trouble-free for the tourists.

On the other hand, in the Middle East, there are very few realistic research on local tourism due to the fact that the region is considered as one of the world's least advanced tourism places where recreation is uncommon and normally viewed as economically irrelevant and culturally unfavorable (Newton, 2018, p2). In 2002, the Middle East witnessed the arrival of roughly 24 million tourists, which includes an almost 10 per cent annual growth since the 1990s. In the past decade, the Middle East has become a rapidly developing tourist destination and has overconfidence on its different uncomfortable tourist destinations (Damanhouri, 2017, p155). In nations like Saudi Arabia, Egypt, and the United Arab Emirates, tourism is regarded as a capital that results in development, growth, and progress in the country.

The research of (Damanhouri, 2017, p156) reveals that tourists in Saudi Arabia usually visit the country for business 
purposes, treatment or medical services, religious reasons, and for families and friends. Hence, Saudi Arabia has religious and family tourists as its most regular visitors. When the satisfaction levels of these tourists were assessed, the study reported that they were satisfied with the tour guides' helpful, responsive, and hospitable services. The increase in the Saudi tour guides' competence is the outcome of the efforts of the Saudi Commission for Tourism and Antiquities (SCTA) to mobilize tour guiding whilst escorting visitors, acquainting them with the tourist spots, giving them appropriate, accurate information in a satisfying way which delivers more improved services generally (Saudi Commission for Tourism and Antiquities, n.d.). The SCTA has granted licenses to numerous tour guides thus far and is endorsing tour guiding through promotional program online.

Additionally, the SCTA helped establish the Tour Guide Committee as the meeting place for every tour guide, developed a symposium labelled Tour Guiding Skills, and opened the website for the Saudi Tour Guide, all for tour guides authorized under the guidelines of the World Federation of Tourist Guide Associations (Saudi Commission for Tourism and Antiquities, n.d.). The SCTA fully acknowledges the value of tour guides in increasing the number of tourists for a tourist destination, which is the reason why it strongly supports the tour guiding career by means of the above-mentioned strategies.

In contrast to Turkey, Israel, and Saudi Arabia, Egypt is currently having problems with its tourism industry. In spite of initial indications of recovery, the untroubled period of the past decade for Egypt appears to remain miles away. Tourism covered almost 20 per cent of Egypt's GDP in 2007 (Oxford Business Group, 2019, p1). Yet, in 2016, after a wave of terrorist events, consequent travel embargos enforced by other countries and overall worries over security, only 5 million tourists were documented, which amounted to a 42 per cent decline from the earlier period. As reported by the Central Agency for Public Mobilization and Statistics, annual tourism numbers have been declining as well, from 147 million in 2010 to 84 million in 2015 (Oxford Business Group, 2019, p1).

One of the reasons Egypt's tourism industry is weakening is the quality of its tour guiding services. The tour guide serves a major part in travel and provides the tourists with an idea of the tourist destinations they work for. Hence, it is highly vital to improve the quality of their services. A number of problems are affecting the tour guiding occupation in Egypt, like the postponement of the release of licenses for the tour guides to provide services outside the capital, feeling of being undervalued by the government, the tension between tourleaders and tour guides, increase in foreign labor, and low salary (Magdy, 2016, p107). Moreover, according to (Abdalla 2007, p37), a research discovered that in spite of having licenses, Egyptian tour guides do not have the necessary knowledge and education to perform competently.

The same is true with Kurdistan. The region has seen massive growth in its tourism industry since 2005. The number of tourists has risen annually until it reached roughly 3 million by 2013. Unfortunately, the conflict against Da'esh has greatly damaged the reputation of Kurdistan as a secure destination for tourists (Rasaiah, 2016, p2). Because of this political disaster, the number of tourists has declined by fifty per cent from 2013 to 2015 (World Bank Group, 2016, p1). The Kurdish government acted immediately but instead of strengthening the tourism industry, it only further weakened it.

One of the reasons for the continuing decline of tourism in Kurdistan is the lack of attention given to tour guides. The bulk of resources were invested in the construction of new restaurants and hotels rather than in the training of tour guides, who are generally scarce in number (Rasaiah, 2016, p2). The lack of qualified tour guides in the region is primarily caused by the difficulty in obtaining a license due to legal restrictions, therefore even the agencies unable to provide, offer them proper guiding opportunity, due to above facts most of graduated tour guide are seeking various job other than professional tour guiding (World Bank Group, 2016, p1). Their competence is also questioned due to the absence of efficient quality assurance processes for tour guiding and international standard of being a tour guide. Even though tourists can freely travel alone in Kurdistan, large numbers of visitors, especially those who are visiting the region for the first time, prefer to have tour guides that could get them easily through checkpoints and speak in their native language (Altaee et al., 2017, p105). Yet, legal barriers and lack of competency make it difficult for tour guides to develop these capabilities.

\section{DISCUSSION AND FINDING}

The analysis has shown that tour guides positively impact tourists' experience and, therefore, their overall satisfaction. Consequently, this could lead to a higher number of visitors in a tourist destination through revisits and word-of-mouth recommendations. The analysis has generated the following findings:

- In Turkey, tourists are highly satisfied with the tour guides' hospitality and most of them plan to revisit and refer the tourist destination to their families and relatives;

- In Israel, tour guides have been found to be highly capable in promoting the Israeli political propaganda against Palestinians by winning the approval and satisfaction of tourists in the country;

- In Saudi Arabia, tourists are satisfied with the accommodating, responsive, and friendly services of tour guides.

- In Egypt, tour guides lack adequate training and support from the government, resulting in the weakening of the country's tourism industry.

- In Kurdistan, competent tour guides are limited in number due to legal restrictions and deficiency of study programs in both theoretical and practically compare to other well-developed tourist countries, on the other hand lack of daring, courageous of tour operator, agencies to provide proper training to and invest on human resource to growth their future businesses. 


\section{FUTURE SCOPE AND RECOMMENDATION}

As shown in these cases, tour guides play a huge role in strengthening the success of tourism improvement for tourist's tour operator as well as tour guide itself. Therefore, the hypotheses of this research have been confirmed.

Universities should provide and offer additional studies on tour guiding practice, education, and training to gain a complete understanding of the ability of practice, education, and training to enhance the capability of tour guides to meet visitors' expectations. Tourism managers and operators should also acknowledge that the performance of tour guides significantly affects tourist satisfaction and could indirectly generate it through the services of tourism operators and the general travelling experience (Kassawnh et al., 2019, p4). Giving tour guides continuous professional training could improve their performance and support the quality of their services.

Generally speaking, government bodies may have to implement a quality performance system for tour guides to evaluate and enrich their personal capabilities, attitudes, and knowledge. Numerous studies have reported certain tour guide characteristics, abilities, and personalities that determine tourist satisfaction (and frustration). These pieces of evidence can be used in the creation of guidelines for tour guide professional development and training (Liu \& Deng, 2017, p212). A vital discovery by numerous researchers is that qualified guides who have undertaken training lead to greater tourist satisfaction levels (Lin et al., 2018, p105), and this fact should be given more attention by governments and tourism businesses.

These findings can also be applied to the development of tour guide training with regard to recognising and appreciating the various cultural backgrounds and expectations of visitors from different cultures, as well as tour guides' attitudes, knowledge, and abilities that are relevant and suitable to different tourists. For instance, informational training led to, and enhanced the accuracy of, understanding official to tourists and increased tourist satisfaction (Sandaruwani \& Gnanapala, 2016, p62). Inadequately trained tour guides appear to lack the capability to understand and describe the civilisations and culture of a tourist destination.

\section{CONCLUSION}

In conclusion, it is clear from the discussion how valuable tour guides are in strengthening the profitability of the tourism industry by attracting more tourists through increased customer satisfaction. Much has been learnt here about how tour guiding can successfully draw the attention and sustain the interest of tourists. This capability generally leads to customer loyalty, satisfaction, and word-of-mouth promotion. Examples from Turkey, Israel, Egypt, Saudi Arabia, and Kurdistan further establish and confirm the hypothesis that tour guides are a dynamic human resource for the tourism industry as they can boost the tourists through their competency and capabilities at giving tourist destination.

\section{REFERENCES}

Abdalla, M. G. (2007). Egypt's image as a tourist destination--- A perspective of foreign tourists, Tourismos: An International Multidisciplinary Journal of Tourism, 3(1), 36-65.

https://mpra.ub.uni-muenchen.de/25374/1/MPRA_paper_25374.pdf

Aldujayn, M. (2018). Impacts of the Saudi tourist phenomenon on Turkey's tourism industry: Examples from Trabzon, King Faisal Center for Research and Islamic Studies, 38(1439), 1-30. https://www.kfcris.com/pdf/c81029e56a18df5e5d4230c2c7ab78835b41 c8696d4af.pdf

Alqasis, A. and Kassis, D. (2015). Status of tourism legislation in Palestine, Alternative Tourism Journal, 1-52. URL: atg.ps/en/wpcontent/uploads/.../Status-of-Tourism-Legislation-inPalestine_ATG.pdf

Altaee, H., Tofiq, A., and Jamel, M. (2017). Promoting the tourism industry of Kurdistan region of Iraq (Halabja province as a case study). Journal of Tourism and Hospitality Management, 5(1), 103-111. URL: https://pdfs.semanticscholar.org/2506/a7d8a34ae8cb23f7439816676eb3 b8ded0a2.pdf

Ap, J. and Wong, K.F. (2001). Case Study on Tour Guiding: Professionalism, Issues and Problems.Tourism Management. 22(1): 551-563. https://www.sciencedirect.com/science/article/abs/pii/S0261517701000 139

Cetinkaya, M. and Oter, Z. (2016). Role of tour guides on tourist satisfaction level in guided tours and impact on re-visiting intention: A research in Istanbul, European Journal of Tourism, Hospitality and Recreation, 7(1), 40-54.

https://content.sciendo.com/downloadpdf/journals/ejthr/7/1/article$\mathrm{p} 40 . \mathrm{xml}$

Cohen, E. (1985). The Tourist Guide: The Origins, Structure and Dynamics of a Role. Annals of Tourism Research. 2 (1): 5-29. https://www.sciencedirect.com/science/article/abs/pii/01607383859003 74

Damanhouri, A. (2017). Study of the social and cultural aspects of Saudi tourists and evaluate the services provided to tourist of Saudiarabia An applied study for the tourism sector in the kingdom of Saudi Arabia, InternationalBusinessResearch, $\quad 10(1), \quad 153-162$. www.ccsenet.org/journal/index.php/ibr/article/download/65144/35310

Huang et al. (2010). Tour Guide Performance and Tourist Satisfaction: a Study of the Package Tours in Shanghai, Journal of Hospitality and Tourism Research 34(1):3-33. https://www.researchgate.net/publication/235640219_Tour_Guide_Perf ormance_and_Tourist_Satisfaction_a_Study_of_the_Package_Tours_in _Shanghai

Kassawnh, M., Al-Balqa, I., Yarmouk, H., and Najdawi, B. (2019). The impact of behaviors and skills of tour guides in guiding tourist groups, African Journal of Hospitality, Tourism and Leisure, 8(1), 1-13. https://www.ajhtl.com/uploads/7/1/6/3/7163688/article_6_vol_8__1_2 019.pdf

Lin, Y., Lin, M., and Chen, Y. (2018). Examining the impact of tour guides' professional competences on service quality tourist satisfaction and repurchase intentions towards package tour products, Journal of Tourism and Hospitality Management, 6(2), 102-114. http://jthmnet.com/vol-6no-2-december-2018-abstract-9-jthm

Liu, Y. and Deng, X. (2017). Study of the tour guide interactive quality's impact on the tourist re-travelling intention based on the tourist's perceived value: A case study of Bali traveling, European Scientific Journal, 210 220. https://eujournal.org/index.php/esj/article/viewFile/9473/8982

Magdy, H. (2016). Challenges affecting the quality service of the tour guide in Egypt, Journal of Tourism, Culture, and Territorial Development, 13, 107-116. https://almatourism.unibo.it/article/view/6013

Newton, K. (2018). Can Saudi Arabia become a tourist destination? viewed 30 May 2019, https://www.mei.edu/publications/can-saudi-arabia-becometourism-destination 
Oxford Business Group (2019). Egypt sees growth in visitor numbers and tourism revenue, viewed 18 May 2019, $<$ https://oxfordbusinessgroup.com/overview/road-recovery-improvingvisitor-numbers-and-sector-revenues-lead-renewed-optimism.

Poudel, S. and Nayaupane, G. P. (2013), The Role Of Interpretative Tour Guiding In Sustainable Destination Management: A Comparison Between Guided And Non-guided Tourists, Journal of Travel Research, 52, pp.659-72.

https://journals.sagepub.com/doi/abs/10.1177/0047287513478496

Prakash, M. and Chowdhary, N. (2010) Becoming a Tour Guide: Analysing the Motivations. Journal of Tourism - Studies and Research in Tourism 9(9):5-13.

https://www.researchgate.net/publication/227576703_Becoming_a_tou r_guide_Analyzing_the_motivations

Prakash, M., Chowdhary, N. and Sunayana (2011). Tour guiding: Interpreting the challenges. Turismos: An International Multidisciplinary Journal of Tourism. 6(1): 65-81.

http://www.chios.aegean.gr/tourism/VOLUME_6_No2_art04.pdf

Rasaiah, J. (2016). The future of tourism in Iraqi Kurdistan: Opportunities and challenges, viewed 5 June 2019, http://www.meri-k.org/publication/thefuture-of-tourism-in-iraqi-kurdistan-opportunities-and-challenges/

Şahin, S. (2012). Intercultural Communication Efficiencies of Tourist Guides: The Perceptions of German, English and Russian Tourists. (Unpublished Ph.D. Thesis). Turkey: Balıkesir University, Graduate School of Social Sciences.

https://www.researchgate.net/publication/223451929_Tour_guide_com munication_competence_French_German_and_American_tourists'_per ceptions

Sandaruwani, J. and Gnanapala, A. (2016). The role of tourist guides and their impacts on sustainable tourism development: A critique on Sri Lanka, Tourism, Leisure and Global Change, 3, 62-73. https://www2.nau.edu/nabejp/ojs/index.php/igutourism/article/view/300

Saudi Commission for Tourism and Antiquities (n.d.) Tourism investment in Saudi Arabia. Riyadh, SCTA.https://scth.gov.sa/.../TourismInvestment/SupportTourismInvest ment/.../Touristic_inve..

Sharpley, R. and Forster, G. (2003). The implications of Hotel Employee Attitudes for the Development of Quality Tourism: The Case of Cyprus. Tourism Management. 24(6): 687-697.

https://www.sciencedirect.com/science/article/abs/pii/S0261517703000 $44 \mathrm{X}$
Staff, T. (2018). Israel saw record-breaking 4 million tourists in 2018, says tourism ministry, viewed 17 May 2019, < https://www.timesofisrael.com/israel-saw-record-breaking-4-milliontourists-in-2018-says-tourism-ministry/>.

Stein, R. (2008). Souvenirs of conquest: Israeli occupations as tourist events, International Journal of Middle East Studies, 40, 647-669. URL: https://fds.duke.edu/db/attachment/1211

Tsai, C. Y., Wang, M. T. and Tseng, H. T. (2015). The impact of tour guides' physical attractiveness, sense of humor, and seniority on guide attention and efficiency. Journal of Travel \& Tourism Marketing, 33(6), 824-836. https://www.tandfonline.com/doi/abs/10.1080/10548408.2015.1068264

Weiler, B., Black, R. and Torland, M. (2014), Tour Guiding Research and Scholarship: A Review Of 50 Years of Research [online], In: Chien, P.Monica. CAUTHE 2014: Tourism and Hospitality in the Contemporary World: Trends, Changes and Complexity, Brisbane: School of Tourism, The University of Queensland, 2014, pp. 1181-85.

World Bank Group (2016). Kurdistan region of Iraq: Reforming the economy for shared prosperity and protecting the vulnerable. Iraq: Kurdistan Regional Government. Reforming\%20the $\% 20$ KRG\%20Reforming\%20the\%20Econo...

Yamada, N. (2011), Why Tour Guiding Is Important For Ecotourism: Enhancing Guiding Quality With The Ecotourism Promotion Policy In Japan, Asia Pacific Journal of Tourism Research, 16 (2), pp. 139-152. https://www.researchgate.net/publication/254240516_Why_Tour_Guid ing_is_Important_for_Ecotourism_Enhancing_Guiding_Quality_with_t he_Ecotourism_Promotion_Policy_in_Japan

Yin, R., (2014). Case Study Research Design and Methods. Thousand Oaks, CA: Sage Publications.

Yu, X., Wailer, B. and Ham, S. (2004) Cultural Mediation in Guided Tour Experiences: A case Study of Australian Guides of Chinese Tour groups. Working paper 44/04: Monash University. Retrieved online from: http://www.buseco.monash.edu.au/mgt/research/workingpapers/2004/wp44-04.pdf

Zhang, H. Q. and Chow, I. (2004) Application of Importance-performance Model in Tour Guides' Performance: Evidence from Mainland Chinese Outbound Visitors in Hong Kong. Tourism Management, 25, 81 - 91.

https://www.sciencedirect.com/science/article/abs/pii/S0261517703000 645 